\title{
Article \\ Genomic Diversity of CRESS DNA Viruses in the Eukaryotic Virome of Swine Feces
}

\author{
Enikő Fehér ${ }^{1}$, Eszter Mihalov-Kovács ${ }^{1}$, Eszter Kaszab ${ }^{1}$, Yashpal S. Malik ${ }^{2} \mathbb{D}$, Szilvia Marton ${ }^{1}$ \\ and Krisztián Bányai 1,3,* \\ 1 Veterinary Medical Research Institute, Hungária Krt 21, H-1143 Budapest, Hungary; \\ feher.eniko@vmri.hu (E.F.); kovacsesztermail@gmail.com (E.M.-K.); kaszab.eszter@vmri.hu (E.K.); \\ marton.szilvia@vmri.hu (S.M.) \\ 2 College of Animal Biotechnology, Guru Angad Dev Veterinary and Animal Sciences University, \\ Ludhiana 141004, Punjab, India; malikyps@gmail.com \\ 3 Department of Pharmacology and Toxicology, University of Veterinary Medical Research, István Utca. 2, \\ H-1078 Budapest, Hungary \\ * Correspondence: bkrota@hotmail.com
}

Citation: Fehér, E.; Mihalov-Kovács, E.; Kaszab, E.; Malik, Y.S.; Marton, S.; Bányai, K. Genomic Diversity of CRESS DNA Viruses in the Eukaryotic Virome of Swine Feces. Microorganisms 2021, 9, 1426. https://doi.org/10.3390/ microorganisms 9071426

Academic Editor: Stefan Vilcek

Received: 12 May 2021

Accepted: 21 June 2021

Published: 1 July 2021

Publisher's Note: MDPI stays neutral with regard to jurisdictional claims in published maps and institutional affiliations.

Copyright: (c) 2021 by the authors. Licensee MDPI, Basel, Switzerland. This article is an open access article distributed under the terms and conditions of the Creative Commons Attribution (CC BY) license (https:// creativecommons.org/licenses/by/ $4.0 /)$.

\begin{abstract}
Replication-associated protein (Rep)-encoding single-stranded DNA (CRESS DNA) viruses are a diverse group of viruses, and their persistence in the environment has been studied for over a decade. However, the persistence of CRESS DNA viruses in herds of domestic animals has, in some cases, serious economic consequence. In this study, we describe the diversity of CRESS DNA viruses identified during the metagenomics analysis of fecal samples collected from a single swine herd with apparently healthy animals. A total of nine genome sequences were assembled and classified into two different groups (CRESSV1 and CRESSV2) of the Cirlivirales order (Cressdnaviricota phylum). The novel CRESS DNA viral sequences shared $85.8-96.8 \%$ and $38.1-94.3 \%$ amino acid sequence identities for the Rep and putative capsid protein sequences compared to their respective counterparts with extant GenBank record. Data presented here show evidence for simultaneous infection of swine herds with multiple novel CRESS DNA viruses, including po-circo-like viruses and fur seal feces-associated circular DNA viruses. Given that viral genomes with similar sequence and structure have been detected in swine fecal viromes from independent studies, investigation of the association between presence of CRESS DNA viruses and swine health conditions seems to be justified.
\end{abstract}

Keywords: CRESS DNA virus; swine; metagenome; phylogenetic analysis; Hungary

\section{Introduction}

Circular Rep-encoding (replication-associated protein encoding) single-stranded DNA (CRESS DNA) viruses form a highly diverse group of small viruses that have been detected worldwide in prokaryotes and eukaryotes, as well as in environmental samples [1,2]. At present, the classified eukaryotic CRESS DNA viruses belong to seven virus families of the Cressdnaviricota phylum (Shotokuvirae kingdom, Monodnaviria realm), including Bacilladnaviridae, Nanoviridae, Smacoviridae, Geminiviridae, Genomoviridae, Redondoviridae, and Circoviride [3]. The genome of CRESS DNA viruses identified in eukaryotic organisms is typically 1-6 kilobases long and contains two main ORFs encoding the Rep and the capsid (Cp) proteins in variable orientation [2-4]. In addition, a number of other CRESS DNA viruses could not be classified yet, and the diversity of the genomic sequences poses challenges to experts in the field of virus taxonomy. Although rep is conserved and may be distinctive for variable CRESS DNA viruses, description of endogenous rep-like elements in eukaryote genomes draws attention to the appropriate selection of methods and usage of complete genome sequences for the classification of these viruses $[5,6]$.

Members of the Circoviridae, Smacoviridae, and Redondoviridae family have been characterized as animal-associated viruses $[3,7,8]$. Although these families include a continuously 
expanding number of viruses, only a few of those have been proved to be pathogenic. One of the known porcine circoviruses, Porcine circovirus 2, is associated with multisystemic diseases in swine, posing threat to swine herds and losses for the breeders [9]. Besides that, both classified and unclassified CRESS DNA viruses have been identified in fecal samples of both healthy and diseased pigs [9-21]. The microbial community of the swine intestine is highly complex, and, as of now, very little is known about how the viruses, including these non-classified porcine-associated CRESS DNA viruses, interact with host cells and other microbes. In this study, we examined the occurrence of CRESS DNA viruses in porcine fecal specimens originally collected for metagenomic analysis of eukaryotic viruses. Representative genomes of novel viruses that showed similarities with porcine circovirus-like (po-circo-like) viruses and fur seal feces-associated circular DNA viruses were sequenced and characterized $[16,17]$. The study confirms high occurrence of diverse CRESS DNA viruses in the swine feces.

\section{Materials and Methods}

\subsection{Sample Processing and Random PCR for Metagenomics}

Metagenomic analysis was conducted from fecal samples of 23 swine (piglets $n=5$, weaned pigs $n=8$, fattening pigs $n=6$, and breeding swine $n=4$ ) collected in a farm in Tiszavasvári, Hungary in 2012. Fifty to one hundred $\mathrm{mg}$ feces were homogenized in $1 \mathrm{~mL}$ phosphate-buffered saline and centrifuged for $10,000 \times g$ for $5 \mathrm{~min}$. Nucleic acid was extracted from the supernatant with Direct-zol RNA Miniprep kit (Zymo Research, Irvine, CA, United States) omitting DNase treatment. Five $\mu \mathrm{L}$ nucleic acid was denatured at $95{ }^{\circ} \mathrm{C}$ for $5 \mathrm{~min}$, after addition of $1 \mu \mathrm{L}$ of $25 \mu \mathrm{M}$ FR26RV-N anchored random hexamer oligonucleotide, and was reverse transcribed [22]. The $25 \mu \mathrm{L}$ reverse transcription reaction mixture contained the denaturation mixture, $400 \mu \mathrm{M}$ of dNTP, 1x AMV RT Buffer, and 1U of AMV Reverse Transcriptase (Promega, Madison, WI, United States), and was incubated at $25{ }^{\circ} \mathrm{C}$ for $10 \mathrm{~min}, 42{ }^{\circ} \mathrm{C}$ for $60 \mathrm{~min}$, and $70{ }^{\circ} \mathrm{C}$ for $15 \mathrm{~min}$. Randomized amplification was carried out in $25 \mu \mathrm{L}$ PCR mixture containing $400 \mu \mathrm{M}$ of dNTP, $1 \mu \mathrm{M}$ of FR20RV primer, 1x DreamTaq Buffer, 2.5 U of DreamTaq DNA Polymerase (Thermo Scientific, Waltham, MA, United States), and $3 \mu \mathrm{L}$ of the cDNA. The reaction conditions consisted of an initial denaturation step at $95^{\circ} \mathrm{C}$ for $3 \mathrm{~min}, 40$ cycles of amplification with the steps of $95^{\circ} \mathrm{C}$ for $30 \mathrm{~s}, 48{ }^{\circ} \mathrm{C}$ for $30 \mathrm{~s}$, and $72{ }^{\circ} \mathrm{C}$ for $2 \mathrm{~min}$, followed by a final elongation step at $72{ }^{\circ} \mathrm{C}$ for $8 \mathrm{~min}$.

\subsection{Sequencing}

The amplified nucleic acid was subjected to DNA library preparation and sequenced with the Ion Torrent Personal Genome Machine ${ }^{\mathrm{TM}}$ PGM System (Thermo Fisher Scientific, Waltham, MA, USA). Enzymatic fragmentation and adapter ligation of the PCR products was performed with NEBNext®Fast DNA Fragmentation \& Library Prep Set for Ion Torrent $^{\mathrm{TM}}$ (New England Biolabs, New England Biolabs, Hitchin, UK) and the Ion Xpress ${ }^{\mathrm{TM}}$ Barcode Adapters kit (Thermo Fisher Scientific, Waltham, MA, USA). The barcoded samples were purified with Geneaid Gel/PCR DNA Fragments Extraction Kit (Geneaid Biotech, Taipei, Taiwan), and products between 300 and $350 \mathrm{bp}$ were retrieved from $2 \%$ precast gel (Thermo Fisher Scientific, Waltham, MA, USA). The fragments were amplified using the reagents of the NEBNext ${ }^{\circledR}$ Fast DNA Fragmentation \& Library Prep Set for Ion Torrent kit (New England Biolabs, New England Biolabs, Hitchin, UK). The steps of the procedure were initial denaturation at $98^{\circ} \mathrm{C}$ for $30 \mathrm{~s}$, followed by 12 amplification cycles at $98{ }^{\circ} \mathrm{C}$ for $10 \mathrm{~s}, 58{ }^{\circ} \mathrm{C}$ for $30 \mathrm{~s}$, and $72{ }^{\circ} \mathrm{C}$ for $30 \mathrm{~s}$, and final elongation at $72{ }^{\circ} \mathrm{C}$ for $5 \mathrm{~min}$. The amplified library DNA was purified from agarose gel and was quantified with Qubitß2.0 Fluorometer using Qubit ${ }^{\mathrm{TM}}$ dsDNA BR Assay Kit (Thermo Fisher Scientific, Waltham, MA, USA). Emulsion PCR of the mixed products were processed using Ion PGM ${ }^{\mathrm{TM}}$ Template Kit and OneTouch ${ }^{\mathrm{TM}}$ v2 instrument (Thermo Fisher Scientific, Waltham, MA, USA) according to the instructions. Templated bead enrichment with Ion OneTouch ${ }^{\mathrm{TM}} \mathrm{ES}$ machine was 
performed according to the $200 \mathrm{bp}$ sequencing protocol (Thermo Fisher Scientific, Waltham, MA, USA). The sequencing was carried out using Ion PGM ${ }^{\text {TM }}$ Sequencing Kit on a 316 chip.

\subsection{Amplification Of Complete Viral Sequences}

The complete genome of CRESS DNA viruses was amplified with PCR in mixtures containing $200 \mathrm{nM}$ of each primer (Table 1), $200 \mu \mathrm{M}$ of dNTP mix, 1x Phusion Green buffer, $0.3 \mathrm{U}$ of Phusion DNA Polymerase (Thermo Fisher Scientific, Waltham, MA, USA), and $2 \mu \mathrm{L}$ nucleic acid. The cycling protocol consisted of a denaturation step at $98{ }^{\circ} \mathrm{C}$ for $30 \mathrm{~s}$, 45 cycles of amplification with the steps of $98^{\circ} \mathrm{C}$ for $10 \mathrm{~s}$, primer annealing (temperatures in Table 1) for $30 \mathrm{~s}$ and $72{ }^{\circ} \mathrm{C}$ for $2 \mathrm{~min}$, followed by a final extension step at $72{ }^{\circ} \mathrm{C}$ for $10 \mathrm{~min}$. The PCR products were purified from agarose gel (Geneaid Gel/PCR DNA Fragments Extraction Kit, Geneaid Biotech, Taipei, Taiwan) and were subjected to library preparation and sequencing using the protocol described above.

Table 1. Primer sequences and annealing temperature used for the back-to-back PCR amplification of complete genomes characterized in this study.

\begin{tabular}{|c|c|c|c|c|c|}
\hline $\begin{array}{l}\text { Primer } \\
\text { Name }\end{array}$ & Region & $\begin{array}{l}\text { Sequenced } \\
\text { Genome }\end{array}$ & Reference Strains & Annealing & Primer Sequences * \\
\hline $\begin{array}{l}\text { CVLV4-F } \\
\text { CVLV4-R }\end{array}$ & ORF1 & $\begin{array}{l}288 \_4 \\
302 \_4\end{array}$ & po-circo-like virus 21 & $53^{\circ} \mathrm{C}$ & $\begin{array}{c}\text { 5'-ATCTTTGGTCTTGCATTGTTGC-3' } \\
\text { 5'-CTTCAAGGCTATCTTATCCTMCC-3' }\end{array}$ \\
\hline $\begin{array}{l}\text { CVLV5-F } \\
\text { CVLV5-R }\end{array}$ & rep & $\begin{array}{l}302 \_5 \\
303 \_5 \\
453 \_5\end{array}$ & po-circo-like virus 41 & $58^{\circ} \mathrm{C}$ & $\begin{array}{c}\text { 5'- GACGGTTTTGACCCGTCAACAC-5' } \\
\text { 5'-CCACCACTTGTCAAACGGTTTGAAG-3' }\end{array}$ \\
\hline $\begin{array}{l}\text { CVLV7-F } \\
\text { CVLV7-R }\end{array}$ & ORF-2 & $\begin{array}{l}303 \_7 \\
453 \_7\end{array}$ & po-circo-like virus 51 & $53^{\circ} \mathrm{C}$ & $\begin{array}{c}\text { 5'-CTGCACCAATAGAAGATGGTAG-3' } \\
\text { 5'-GAGGTTCTGGAATTAAACCATTGTC-3' }\end{array}$ \\
\hline $\begin{array}{l}\text { CVLV2-F } \\
\text { CVLV2-R }\end{array}$ & cap & $\begin{array}{l}306 \_2 \\
451 \_2\end{array}$ & FSfaCVc & $53^{\circ} \mathrm{C}$ & $\begin{array}{l}\text { 5'-TAYCTTATGTGGACACATTTACCG-3' } \\
\text { 5'-TAAATTGTGGTTWGGACCATCC-3' }\end{array}$ \\
\hline
\end{tabular}

* The primers were designed using the contigs obtained by viral metagenomics.

\subsection{Software}

For viral metagenomics, raw sequence reads were trimmed and quality-controlled using CLC Genomics Workbench (version 9.0; 27/02/2016; http:/ / www.clcbio.com). The minimal read length parameter was set to 35 . Trimmed reads were taxonomically binned using Diamond v0.8.3 versus NCBI-NR [23]. After classification, the output files were analyzed and visualized by MEGAN6 Ultimate Edition [24].

The complete CRESS DNA viral genomes were assembled with Geneious Prime®2020.2.4 software (https: / / www.geneious.com/, accessed on 16 September 2020) with mapping to references and de novo assembly of the reads. Coding sequences were predicted using the ORF Finder software (https:/ / www.ncbi.nlm.nih.gov / orffinder, accessed on 16 September 2020) and putative ORFs encoding proteins of $\geq 100$ aa were taken into consideration. Sequence alignments (using MAFFT algorithm) and pairwise sequence identities (using complete deletion option) were generated with Geneious Prime®2020.2.4 and Mega6 software, respectively. Amino acid sequence-based maximum likelihood and neighbor joining trees were obtained with the PhyML and the Mega6 software, respectively, with the best fit models $[25,26]$. SHlike (maximum likelihood tree) and bootstrap (neighbor joining tree) supports were used to estimate the confidence of tree topology. Recombination analysis was performed with the Recombination Detection Program v4 [27].

\section{Results}

\subsection{Results of Viral Metagenomics and Focus on CRESS DNA Viruses}

Metagenomic sequencing was conducted on 23 fecal samples collected from a swine farm in Hungary. Bioinformatic analysis of Ion Torrent reads identified a range of 2 to 7857 sequence reads per sample that mapped to viruses of eukaryotic organisms. These viral 
sequences could be classified into 12 virus families or orders (Astroviridae, Anelloviridae, Caliciviridae, Cirlivirales, Herpesvirales, Orthomyxoviridae, Parvoviridae, Picobirnaviridae, Picornaviridae, Reoviridae, Smacoviridae, Tobaniviridae; Figure 1a). All 23 samples contained viral sequences, and the number of identified viral families/orders ranged from 2 to 15 per sample.

(a)

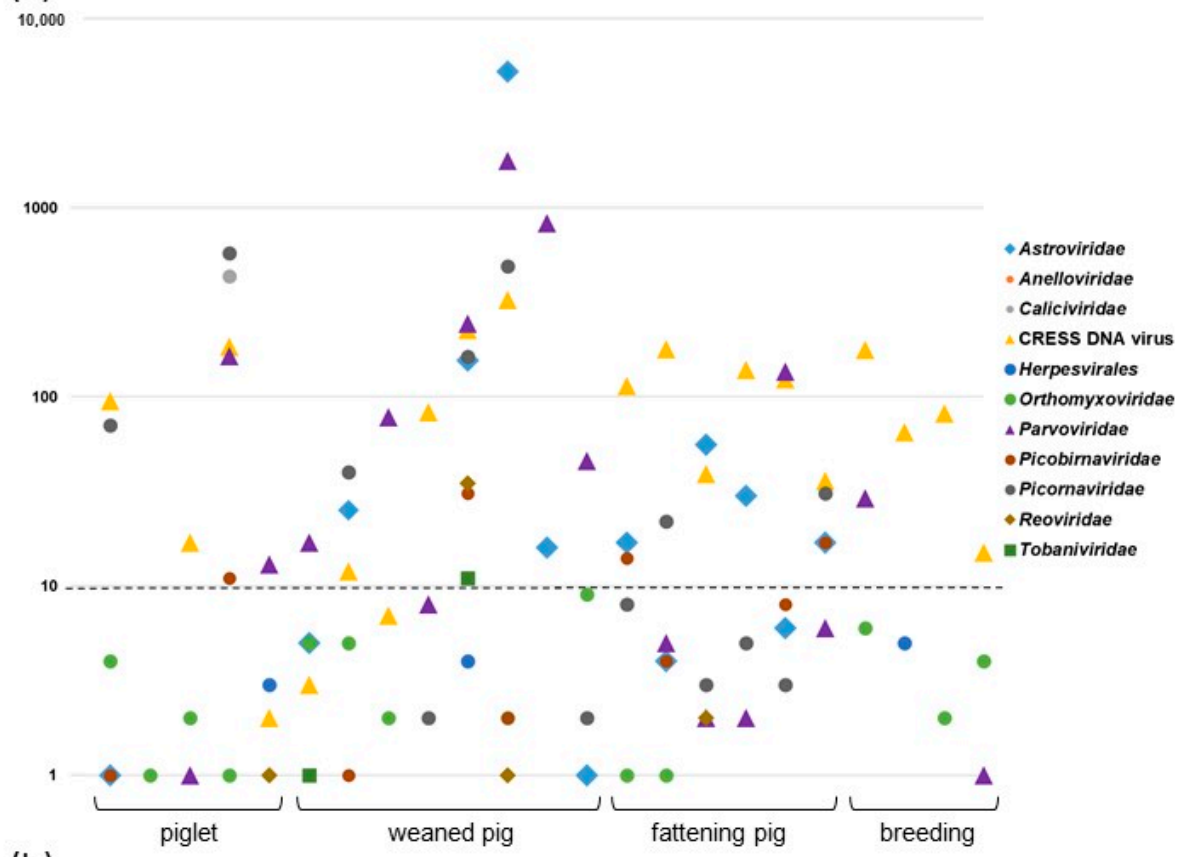

(b)

1000

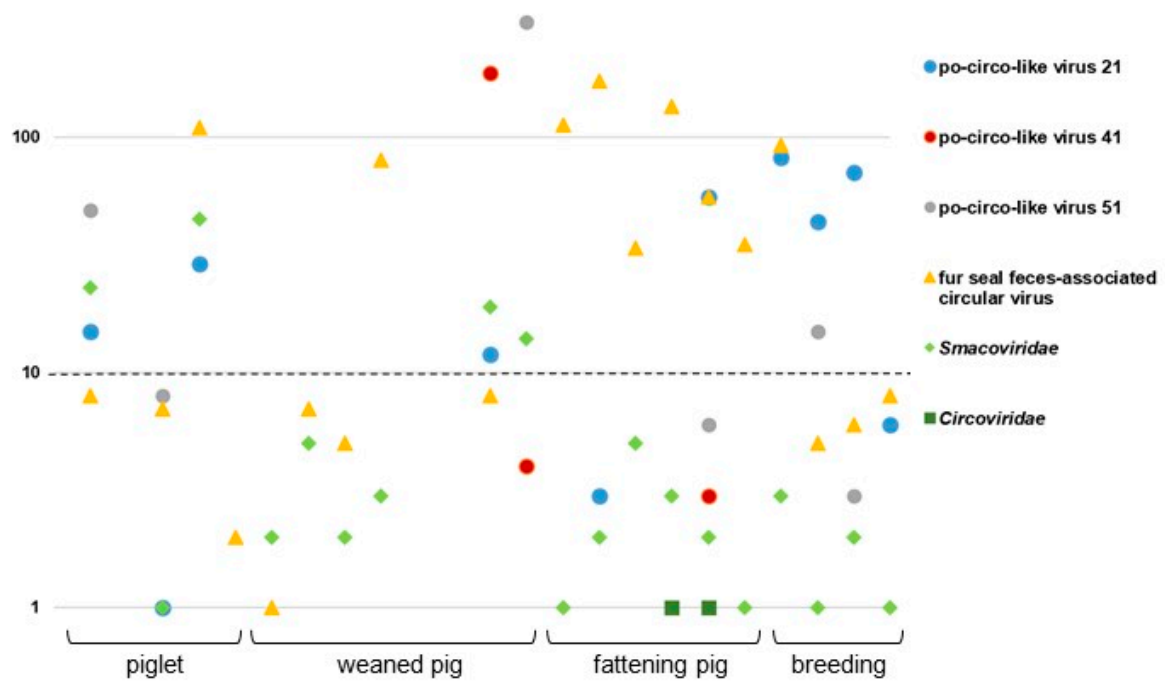

Figure 1. Virus families (a) and CRESS DNA viruses (b) represented in the fecal virome of swine investigated in this study. The read number for each viral group ( $\mathrm{Y}$ axis) is plotted against the individual specimens sorted by age group. Symbols of viral taxa on the right are used in the plot. Detection of viral taxa represented by low read numbers $(n<10$; dashed line) should be considered with cautions due to possible misidentification. 
The most genetically diverse virus group observed was CRESS DNA viruses that included the members of the Cirlivirales order and the Smacoviridae family. All additional analyses were conducted to characterize these viruses (Figure 1b).

Metagenomic analysis mapped numerous sequence reads to the genomes of CRESS DNA viruses in nearly all (20/23) samples (Figure 1). Based on BLAST search, the vast majority of reads (1-312 reads per virus per sample) in these 20 samples filtered for CRESS DNA viruses mapped to the sequences of porcine circovirus-like viruses (po-circo-like virus 21 and 22, 41 and 51, GenBank accession numbers: JF713716-719) and fur seal feces-associated circular DNA viruses (FSfaCVs, GenBank accession numbers: KF246569, LC133373, MK462122) [14,16,17,19,28].

Besides the reads associated with po-circo-like viruses and FSfaCVs, only a few reads ( 1 to 45 per sample) aligned with other known CRESS DNA viruses with up to 93\% nt identities. The BLAST revealed that the reads fitted to sequences of strains from the Smacoviridae family. In addition to these viruses, two samples contained Porcine circovirus 2 origin sequences, although at low quantity (a single sequence read in each), which raises the question of whether these sequence reads were true hits (Figure 1). In this study, we did not analyze these additional (putative) CRESS DNA virus sequences.

To determine the whole genome sequence of selected CRESS DNA viruses that were predicted to represent new viral variants, four back-to-back primer sets were designed for the amplification of complete viral genome sequences. Altogether, 15 PCR products of nine fecal samples were subjected to next-generation sequencing. Of these, nine amplicons from six fecal samples could be assembled to a complete genome; sequence ambiguities were seen in six long PCR products implying a mixture of highly similar sequences. Regarding the sequencing results, 17,075 to 28,428 sequence reads mapped to the assembled genomes with an average sequencing depth of 1178X (range, 635X to 1581X). Results indicated that the majority of sequences belonged to po-circo-like CRESS DNA viruses, while a minority of sequences were variant FSfaCVs.

\subsection{Genomic Characterization of Novel Po-Circo-Like CRESS DNA Viruses}

The longest characterized genomes of 3926 bp belonging to the strains 288_4 and 302_4 showed 99.3\% genome-wide nt identity with each other. The genome of the novel strains shared 85.3-87.7\% identity with po-circo-like virus 21 and 22, GX14, GX15, and GX19 (GenBank Acc. no. MN263296-298), and 80.2\% identity with the genome of the bovine origin bo-circo-like virus (GenBank Acc. no. MH316857) $[16,19,29]$. The predicted ORFs of the genome of strain 288_4 and 302_4 represented ambisense orientation and, using the conserved nonanucleotide motif for the determination of gene orientation, the rep may be located on the complementary strand of the replicative dsDNA intermediate (Figure 2, Table 1). According to the classification of Rosario et al. [4], the genome of these strains share key features with type IV CRESS DNA viruses. 

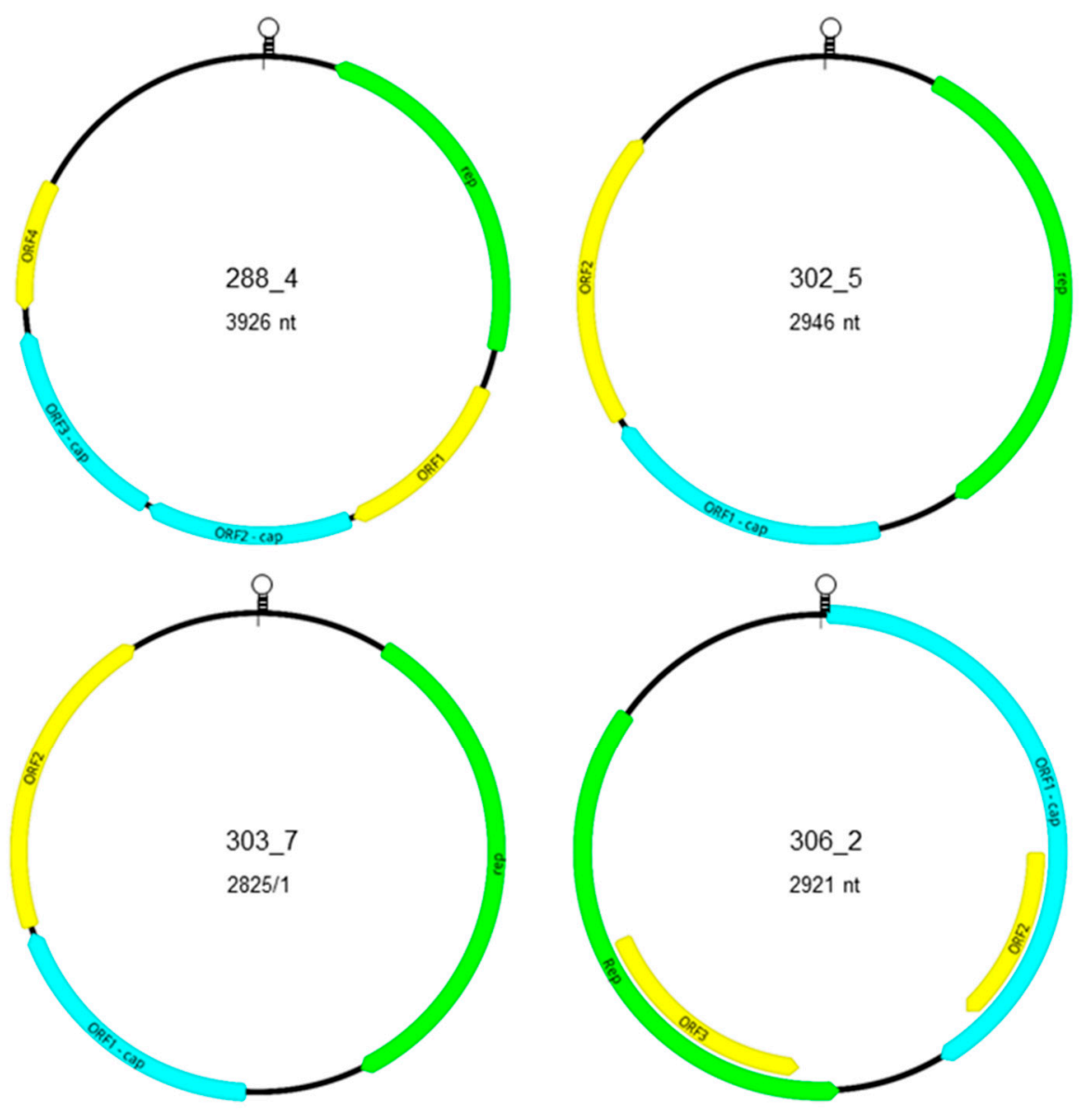

Figure 2. Genome arrangement and putative ORFs of the virus strains described in this study. The loop represents the nonanucleotide motif in the large intergenic region. The colored arrows show the direction and localization of the putative ORFs in the genome: green—rep; blue-cp; yellow-ORFs with unknown function.

The genome of strains 288_4 and 302_4 comprises a minimum of five ORFs, three in sense and two in antisense orientation (Figure 2; Table 2). The predicted rep and other ORFs were also identified in the porcine origin reference sequences with some differences, e.g., ORF3 was split into two smaller ORFs because of an early stop codon in the genome of po-circo-like virus 21. The length and sequence of the ORFs of bo-circo-like virus genome represented more differences compared to that of the porcine origin strains. The rep sequences of strain 288_4 and 302_4 showed 99.7\% nt and aa identities with each other, $92.2-93.1 \% \mathrm{nt}$ and $96.1-96.8 \%$ aa identities with the rep sequence of po-circo-like virus 21, GX14, GX15, and GX19, and 87.7-89.6\% nt and 91.6-93.9\% aa identities with the same region of po-circo-like virus 22 and bo-circo-like virus. Other ORFs of strain 288_4 and 302_4 showed $96.1-100 \%$ nt and aa identities with each other. The ORF1 and ORF4 of the strain 288_4 and 302_4 showed $>90 \%$ nt and aa identity with the porcine origin reference sequences, while these values were lower for the ORF2 and ORF3 (75.9-86.3 nt and $74.4-85.6 \%$ aa identity for ORF2, and $49.9-66.8 \%$ nt and $38.1-54.5 \%$ aa identity for ORF3). Despite the sequence variability and lower identities, the N-terminal region of the ORF2 and ORF3 is relatively conserved, and slight accumulation of positively charged aa ( $\mathrm{R}$ and $\mathrm{K}$ ) in the derived protein sequences suggest that the gene products may be capsid proteins. The large intergenic region (LIR) was located between the 3 ' end of the rep and $5^{\prime}$ end of ORF4 in the genome of strain 288_4 and 302_4. The LIRs of these sequences showed $100 \%$ nt identity with each other, and 91.8-95.2\% nt identities with the porcine origin reference sequences. The putative nonanucleotide motif (CAGTATTAC) and the encompassing eight nt long inverted repeats is predicted to form a loop structure. Upstream 
of the nonanucleotide motif four copies of $10 \mathrm{nt}$ long consecutive repeats were found as well. However, inverted repeats were missing that may indicate the lack of loop formation and thus may not be involved in the initiation of genome replication processes.

Table 2. The main characteristics, the position, and the length of the ORFs of novel CRESS DNA genomes described in this study.

\begin{tabular}{|c|c|c|c|c|c|c|c|c|}
\hline \multirow{2}{*}{ Genome } & \multirow{2}{*}{$\begin{array}{l}\text { Genome } \\
\text { Length nt }\end{array}$} & \multirow{2}{*}{$\begin{array}{l}\text { Genome } \\
\text { Type }\end{array}$} & \multirow{2}{*}{$\begin{array}{c}\text { Nonanucleotide } \\
\text { Motif }\end{array}$} & \multicolumn{5}{|c|}{ ORF Position to the Nonanucleotide Motif } \\
\hline & & & & rep & ORF1 & ORF2 & ORF3 & ORF4 \\
\hline $288 \_4$ & 3926 & IV & CAGTATTAC & 1123-191 & $1232-1720$ & $1733-2275$ & $2289-2849$ & 3249-2911 \\
\hline $302 \_4$ & 3926 & IV & CAGTATTAC & 1123-191 & $1232-1720$ & $1733-2275$ & $2289-2849$ & $3249-2911$ \\
\hline $302 \_5$ & 2946 & $\mathrm{~V}$ & TAGTATTAC & $226-1203$ & 1366-1941 & $1956-2543$ & NA & NA \\
\hline $303 \_5$ & 2946 & $\mathrm{~V}$ & TAGTATTAC & $226-1203$ & 1366-1941 & $1956-2543$ & NA & NA \\
\hline 453_5 & 2942 & $\mathrm{~V}$ & TAGTATTAC & 226-1203 & 1365-1940 & 1956-2543 & NA & NA \\
\hline 303_7 & 2825 & $\mathrm{~V}$ & CATTATTAC & 253-1212 & 1437-1964 & 1978-2583 & NA & NA \\
\hline $453 \_7$ & 2825 & $\mathrm{~V}$ & CATTATTAC & $253-1212$ & 1437-1964 & $1978-2583$ & NA & NA \\
\hline $306 \_2$ & 2921 & II & TAGTATTAT & $2478-1423$ & $14-1213$ & $732-1112$ & 2000-1509 & NA \\
\hline 451_2 & 2912 & II & TAGTATTAT & 2469-1414 & 14-1204 & 723-1103 & 1991-1500 & NA \\
\hline
\end{tabular}

NA; not applicable.

The predicted ORFs of the genome of strain 302_5, 303_5, 453_5, 303_7, and 453_7 showed unidirectional organization. The putative nonanucleotide motif and ORFs are located on the viral strand as described for type V CRESS DNA genomes [4] (Figure 2, Table 1). The nonanucleotide motif located in the LIR between the ORF2 and the rep, together with flanking inverted repeats, suggesting loop formation. The putative ORF of rep was found downstream of the nonanucleotide motif that was followed by another two ORFs. Again, the accumulation of positively charged aa at the N-terminal end of the putative gene product implies that ORF1 may encode Cp.

The genome length of strain 302_5, 303_5, and 453_5 was 2946, 2946, and 2942 nt, respectively (Figure 2, Table 1). These genomes represented moderate (82.3-82.4\%) genomewide nt identities with the po-circo-like virus 41 strain. The rep sequences of the novel genomes showed $100 \% \mathrm{nt}$ and aa identity with each other and $90.1 \% \mathrm{nt}$ and $85.8 \%$ aa identity with the reference sequence. The putative Cp-encoding ORF1 of strains 302_5, $303 \_5$, and $453 \_5$ showed $100 \%$ nt and aa identity with each other and $93.5 \%$ nt and $93.7 \%$ aa identity with the po-circo-like virus 41 sequence. The ORF2 sequences of the novel genomes shared $99.5-100 \%$ nt and $98.5-100 \%$ aa identity with each other and $86.5-86.8 \%$ nt and 83.6-84.6\% aa identity with the po-circo-like virus 41 sequence. Regarding the LIR, the Hungarian porcine origin sequences showed $97.9-99.5 \%$ nt identities with each other, and only $56.4-56.8 \%$ nt identity with the LIR of the reference genome. The LIR encoded two repeats of 91,86 , and $84 \mathrm{nt}$ long motifs upstream of the TAGTATTAC nonanucleotide motif in the genome of strains 302_5, 303_5, and 453_4, respectively. The function of these, and additional, short repeats along the LIR is unknown.

The other two strains with type V CRESS DNA genome structure, 303_7 and 453_7, had the smallest genomes (2825 nt) and showed 99.9\% genome-wide nt identity with each other. However, they shared only $87.3 \%$ identity with the genome of the closest reference, the po-circo-like virus 51. The rep of the novel sequences from Hungary showed $99.9 \%$ nt and $100 \%$ aa identity with each other, and $93.2 \%$ nt and $93.8 \%$ aa identity with the rep of the reference strain. The ORF1 of the two novel strains showed $100 \%$ nt and aa identity with each other, and $93.0 \% \mathrm{nt}$ and $94.3 \%$ aa identities with the reference strain sequence. Regarding the ORF2, the two novel strains represented $99.8 \%$ nt and $99.5 \%$ aa identity with each other, but only $79.9-80.1 \% \mathrm{nt}$ and $73.6 \%$ aa identity with the reference sequence. Similarly, the LIR of the two novel sequences showed $99.6 \%$ with each other, and $78.2 \%$ with the LIR of the reference genome. Regarding the genome of strain 303_7, the LIR had a highly complex structure; a 52-nt-long region upstream of the nonanucleotide motif (CATTATTAC) consisted of two 34-nt-long overlapping repeats that could be overlaid by 
three of $16 \mathrm{nt}$ long or six of $6 \mathrm{nt}$ long consecutive repeats. Shorter, $21 \mathrm{nt}$ long, overlapping repeats were detected in the same position within the LIR of strain 453_7 that could be overlaid with two of the 16-nt-long or four of the $6 \mathrm{nt}$ long repeats described for strain 303_7. Of interest, the $16 \mathrm{nt}$ long sequence did not show repeat structure in the LIR of reference sequence. The LIR of 303_7 and 453_7 genomes contained 7 nt long inverted repeats upstream of this complex structure that may imply the formation of loop structure. Downstream of the nonanucleotide motif, 34 nt long repeats were identified in both novel sequences as well, which highly differed from the $38 \mathrm{nt}$ long repeats in the same region of the reference sequence.

\subsection{Genomic Characterization of Novel FSfaCV-Like CRESS DNA Viruses}

The genomes of strains 306_2 and 451_2 were 2921 and 2912 nt long, respectively, and based on the structure of those, could be classified as type II CRESS DNA virus genomes [4] (Figure 2, Table 1). The ORF1 may be encoded on the viral strand downstream of the nonanucleotide motif, while the rep may be located in the complementary replicative strand (Figure 2). The sequences showed $98.6 \%$ genome-wide nt identity with each other, and $89.2-90.8 \%$ nt identities with the genome of reference FSfaCVs. The rep of the novel sequences shared $98.8 \% \mathrm{nt}$ and $98 \%$ aa identity with each other, and $90.9-94.9 \% \mathrm{nt}$ and 87.5-93.4\% aa identities with the reference sequences. Accumulation of positively charged amino acids ( $\mathrm{R}$ and $\mathrm{K}$ ) in the $\mathrm{N}$-terminal region of the ORF1 indicated that it may code for the Cp. The ORF1 of the novel sequences from Hungary shared $98.3 \%$ nt and $98.5 \%$ aa identity with each other, and $88.7-90.4 \%$ nt and $88.5-89.5 \%$ aa identities with the reference sequences. The ORF3 of the novel sequences showed $98.8 \%$ nt and $97.5 \%$ aa identity with each other, and 92.9-96.5\% nt and 86.5-93.9\% aa identities with the reference sequences. The ORF2 of strains 306_2 and 451_2 showed 98.4\% nt and 96\% aa identity among each other; ORF with similar feature could not be identified in the reference genomes. The LIR was located between the $5^{\prime}$ ends of the ORF1 and rep. This sequence of the novel FSfaCV genomes showed $99.8 \%$ nt identity with each other, and 88.4-92.4\% nt identities with the reference sequences. The putative nonanucleotide motif (TAGTATTAC) was surrounded with $10 \mathrm{nt}$ long inverted repeat (GACATAAGGG) that supposed loop formation.

\subsection{Phylogenetic Classification of the Genomes of Novel Porcine CRESS DNA Viruses}

Classification and phylogeny of CRESS DNA viruses is based on the available Rep sequences; thus, to determine the relationship of the novel sequences with other CRESS DNA viruses, we involved this region into phylogenetic analysis using a subset of the reference sequences applied by Krupovic and coworkers [3]. The Rep sequences derived from the genome of different po-circo-like viruses were only distantly related, but grouped together in the phylogenetic tree in a separate branch with unclassified CRESSV2 genomes, including Kirkoviruses (47.1-58.4\% nt and 36.2-51.3\% aa identities for the rep). The Rep sequences derived from the FSfaCVs genome sequences grouped with unclassified CRESSV1 sequences. The FSfaCVs shared as low as $34.5 \%$ nt and $20.3 \%$ aa identities with the pocirco-like viruses, while the latter showed $47.0-54.4 \%$ nt and $37.7-48.6 \%$ aa identities with sequences of members from other po-circo-like viral groups. The CRESSV1 and CRESSV2 groups belong to the Cirlivirales order together with viruses of the Circoviridae family [3] (Figure 3). 
(a)

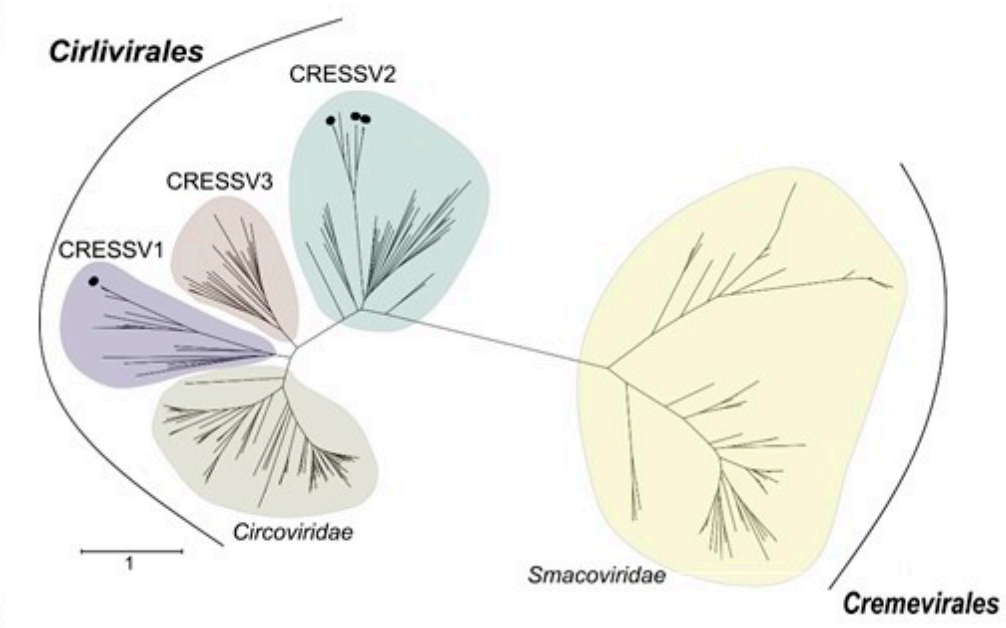

(b)

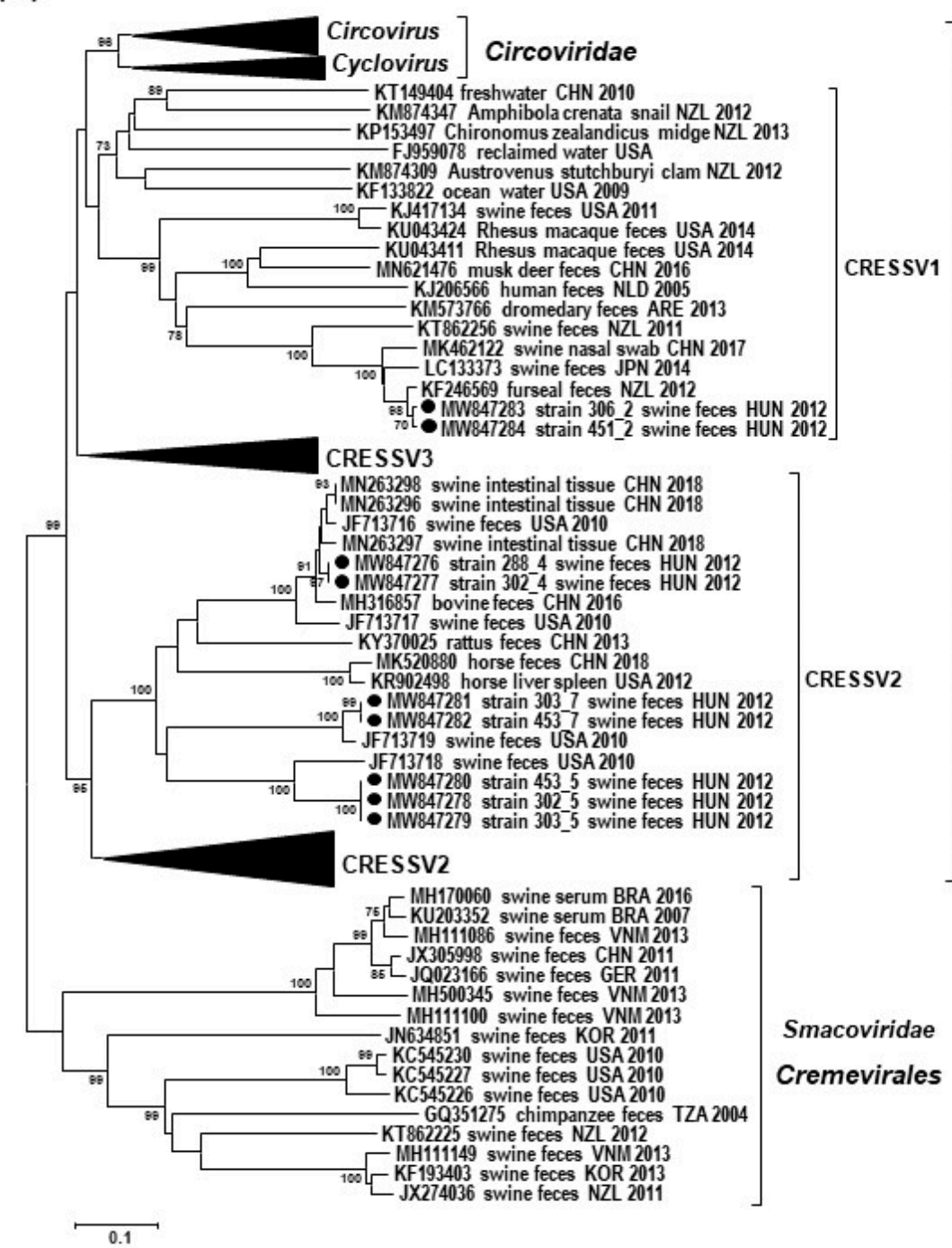

Figure 3. Phylogenetic analysis of the translated rep sequences of the viral genomes described in this study. The Hungarian sequences are highlighted with black dots. (a) Unrooted maximum likelihood phylogenetic tree generated with the PhyML software, LG + F + G + I model, and aLRT SH-like support, using a subset of reference sequences of the Cirlivirales and Cremevirales order taken from Krupovic et al. [3]. The scale bar represents the aa substitutions per site. (b) Unrooted neighbor joining tree generated with the Mega6 software, p-distance model, and 1000 bootstrap replicates using selected CRESS DNA virus reference sequences. Bootstrap values lower than 70 are not shown. The scale bar represents the aa substitutions per site. 


\section{Discussion}

In this study, the occurrence of CRESS DNA viruses were investigated in fecal samples of healthy swine collected in a single Hungarian farm. Based on the results of viral metagenomics, the genomic organization of nine viruses from four viral groups were characterized which represented three different genome types [3]. Although the genomic sequence and organization of the novel po-circo-like viruses (strain 288_4, 302_4, 302_5, 303_5, 453_5, 303_7, and 453_7) from Hungary showed marked differences, some similarities were also noted. The rolling circle replication (RCR) mechanism of CRESS DNA viruses is related to conserved Rep motifs, including N-terminal RCR motifs (I, II, and III), C-terminal superfamily 3 helicase motifs (Walker-A, -B, and Motif C) and an arginine finger, that together have a role in initiation, elongation, and termination of RCR of CRESS DNA viruses of eukaryote origin [2]. The Rep motifs identified in the po-circo-like viruses corresponded to that of the circo- and cycloviral genomes (Table 3). On the other hand, the nonanucleotide motif in the LIR of the 288_4, 302_4, 302_5, 303_5, 453_5, 303_7, and 453_7 genomes, featured as NANTATTAC, was also typical for the genomes of viruses belonging to the Circoviridae family (Table 1). The motifs were surrounded by inverted repeats denoting potential loop formation that may be necessary for the nicking of the DNA strand at the initiation of RCR [2,4,7]. However, the flanking inverted repeats are generally longer (11 nt long) in the circo- and cycloviral genomes. The LIR of the po-circo-like viruses contained repetitive elements that may help the RCR processes [30].

Table 3. Endonuclease (rolling circle replication, RCR) and helicase domain motifs of the Rep sequence of the viral strains described in this study.

\begin{tabular}{|c|c|c|c|c|c|c|}
\hline & \multicolumn{3}{|c|}{ RCR Motifs } & \multicolumn{3}{|c|}{ Superfamily 3 Helicase Motifs } \\
\hline & $\mathbf{I}$ & II & III & Walker-A & Walker-B & Motif C \\
\hline 288_4 & CFTIND & PHIQG & YCTK & GKGKS & VIDDW & ITSN \\
\hline $302 \_4$ & CFTIND & PHIQG & YCTK & GKGKS & VIDDW & ITSN \\
\hline $302 \_5$ & CFTINN & PHIQ̄G & YCSK & GSGKT & VIDDY & VTSN \\
\hline 303_5 & CFTINN & PHIQG & YCSK & GSGKT & VIDDY & VTSN \\
\hline 453_5 & CFTINN & PHIQG & YCSK & GSGKT & VIDDY & VTSN \\
\hline 303_7 & VFTINN & PHIQG & YCSK & GSGKT & LIDDF & ITSN \\
\hline $453 \_7$ & VFTINN & PHIQG & YCSK & GSGKT & LIDDF & ITSN \\
\hline 306_2 & AMTVKN & QHCHI & YLAK & GSGKS & WFDEF & ISTI \\
\hline 451_2 & ALTVKN & QHCHI & YLAK & GSGKS & WFDEF & ISTI \\
\hline
\end{tabular}

The putative nonanucleotide motif in the LIR of FSfaCVs genomes was similar to that of po-circo-like viruses and members of the Circoviridae family, but the RCR and SF3 helicase motifs of the Rep differed from those (Tables 1 and 2). In spite of the similarities in the Rep sequences of the po-circo-like viruses, the members of the Circoviridae family, as well as those of the FSfaCVs, belonged to separated groups of the Cirlivirales order of the CRESS DNA viruses in the phylogenetic trees (Figure 3). In the phylogenetic tree, po-circo-like viruses grouped with CRESSV2, while FSfaCVs clustered with CRESSV1 viruses. Although species demarcation criteria were not defined for CRESSV1 and CRESSV2 viruses, the genetic distance of 302_5, 303_5, and 453_5 (82.3-82.4\% nt identity), as well as 303_7 and $453 \_7$ (87.3\% nt identity) complete genomes from the reference sequences suggested that those may belong to distinct virus species. The comparisons involving different genomic regions revealed the lowest identities for the LIR. Recombination analysis using reference sequences from the Cirlivirales order did not reveal probable recombination events in the sequences of the novel strains (data not shown). However, as CRESS DNA viruses are highly prone to recombination, and the viral genome may consist of sequences originating from the genomes of evolutionary distant taxa of CRESS DNA viruses or from nucleic acid of other viruses, bacteria and plasmid recombination events cannot be ruled out [1,31].

Regarding the putative $\mathrm{Cp}, \mathrm{N}$-terminal accumulation of positively charged aa is characteristic for circoviral capsid proteins. This region may be responsible for nuclear 
localization and for DNA binding during packaging [32]. In the case of the po-circo-like viruses and FSfaCVs, slight accumulation of positively charged aa led us to assign the putative Cp encoding ORFs. However, it is conceivable that gene products of other parts of the genomes may have a role in capsid formation.

Although porcine circoviruses are highly prevalent [9], only traces of Porcine circovirus 2 sequences could be found in some study samples. Unfortunately, no information was available as to whether the animals were vaccinated against this pathogen in that herd. Besides viruses of the Cirlivirales order, smacovirus genomes were also detected in most of our samples. Smacoviruses were identified not only in the feces, but also in serum samples of swine collected in Brazil [20]. Although the low number and quality of the short sequences did not allow more specific analyses, and complete genome sequences were not amplified, smacoviruses seemed to be prevalent in the fecal specimens processed in our study (Figure 1b).

The virome composition of healthy and diseased pigs has been investigated in studies processing fecal, nasal, lymph node, and blood samples collected in numerous geographic areas, including Germany, Sweden, the USA, Brazil, Japan, China, Vietnam, Korea, and New Zealand [10-21,33]. However, the number of studies reporting the simultaneous presence of variable CRESS DNA viruses in the same sample is limited [12,14]. Our eukaryotic viral metagenomic sequencing results showed similarities with these earlier studies in that CRESS DNA viral sequences were frequently detected in the fecal virome of the studied Hungarian pigs. This may be the consequence of environmental contamination due to semiclosed husbandry practices. While smacoviruses were described in serum samples that may suppose infection of the affected pigs [20], the po-circo-like viruses and FSfaCVs were feces-associated or originated from intestinal tissue or nasal samples, thus the source of these viruses remains unknown. Although there are differences in the genomic sequences, closely related CRESS DNA viruses of the Cirlivirales and Cremevirales orders may appear in the intestine of swine and other mammals (e.g., in bovine, fur seal, or primates), regardless of the geographic origin that may imply infection of multiple host species. On the other hand, the CRESS DNA viruses characterized in this study could originate from microbes colonizing the intestinal tract of the hosts, or from other environmental or dietary sources [31,34]. The intense trade of animals and their persistent infection likely contributes to the spread of various viruses that, together with recombination events, may promote emergence of highly diverse viruses and adaptation of those to novel susceptible hosts. Although the pathogenic role of viruses investigated in this study is unknown, which implies that they may be harmless to swine, compliance of the requirements related to animal health and hygiene is of high importance.

Author Contributions: Conceptualization, E.F. and K.B.; methodology, E.F., E.M.-K., and S.M.; software, E.F. and E.K.; validation, Y.S.M. and K.B.; formal analysis, E.F.; data curation, E.F., E.M.-K., and S.M.; writing—original draft preparation, E.F; writing—review and editing, Y.S.M. and K.B.; supervision, K.B.; funding acquisition, K.B. All authors have read and agreed to the published version of the manuscript.

Funding: This research was funded by Momentum program (Hungarian Academy of Sciences), grant number LP2011-10. The funders had no role in the design of the study; in the collection, analyses, or interpretation of data; in the writing of the manuscript, or in the decision to publish the results.

Institutional Review Board Statement: Not applicable.

Informed Consent Statement: Not applicable.

Data Availability Statement: Sequence data were deposited in GenBank under the following accession numbers: MW847276-MW847284.

Conflicts of Interest: The authors declare no conflict of interest. 


\section{References}

1. Kazlauskas, D.; Varsani, A.; Koonin, E.V.; Krupovic, M. Multiple origins of prokaryotic and eukaryotic single-stranded DNA viruses from bacterial and archaeal plasmids. Nat. Commun. 2019, 10, 3425. [CrossRef]

2. Zhao, L.; Rosario, K.; Breitbart, M.; Duffy, S. Eukaryotic circular Rep-encoding single-stranded DNA (CRESS DNA) viruses: Ubiquitous viruses with small genomes and a diverse host range. Adv. Virus. Res. 2019, 103, 71-133. [CrossRef]

3. Krupovic, M.; Varsani, A.; Kazlauskas, D.; Breitbart, M.; Delwart, E.; Rosario, K.; Yutin, N.; Wolf, Y.I.; Harrach, B.; Zerbini, F.M.; et al. Cressdnaviricota: A virus phylum unifying seven families of Rep-encoding viruses with single-stranded, circular DNA genomes. J. Virol. 2020, 94, e00582-20. [CrossRef]

4. Rosario, K.; Duffy, S.; Breitbart, M. A field guide to eukaryotic circular single-stranded DNA viruses: Insights gained from metagenomics. Arch. Virol. 2012, 157, 1851-1871. [CrossRef] [PubMed]

5. Fehér, E.; Székely, C.; Lőrincz, M.; Cech, G.; Tuboly, T.; Singh, H.S.; Bányai, K.; Farkas, S.L. Integrated circoviral rep-like sequences in the genome of cyprinid fish. Virus Genes 2013, 47, 374-377. [CrossRef] [PubMed]

6. Marton, S.; Ihász, K.; Lengyel, G.; Farkas, S.L.; Dán, Á.; Paulus, P.; Bányai, K.; Fehér, E. Ubiquiter circovirus sequences raise challenges in laboratory diagnosis: The case of honey bee and bee mite, reptiles, and free living amoebae. Acta Microbiol. Immunol. Hung. 2015, 62, 57-73. [CrossRef]

7. Rosario, K.; Breitbart, M.; Harrach, B.; Segalés, J.; Delwart, E.; Biagini, P.; Varsani, A. Revisiting the taxonomy of the family Circoviridae: Establishment of the genus Cyclovirus and removal of the genus Gyrovirus. Arch. Virol. 2017, 162, 1447-1463. [CrossRef]

8. Varsani, A.; Krupovic, M. Smacoviridae: A new family of animal-associated single-stranded DNA viruses. Arch. Virol. 2018, 163, 2005-2015. [CrossRef] [PubMed]

9. Saikumar, G.; Das, T. Porcine circovirus. In Recent Advances in Animal Virology; Malik, Y.S., Singh, R.K., Yadav, M.P., Eds.; Springer: Singapore, 2019; pp. 171-195. [CrossRef]

10. Cheung, A.K.; Ng, T.F.; Lager, K.M.; Bayles, D.O.; Alt, D.P.; Delwart, E.L.; Pogranichniy, R.M.; Kehrli, M.E., Jr. A divergent clade of circular single-stranded DNA viruses from pig feces. Arch. Virol. 2013, 158, 2157-2162. [CrossRef] [PubMed]

11. Cheung, A.K.; Ng, T.F.; Lager, K.M.; Alt, D.P.; Delwart, E.L.; Pogranichniy, R.M. Unique circovirus-like genome detected in pig feces. Genome Announc. 2014, 2, e00251-14. [CrossRef]

12. Karlsson, O.E.; Larsson, J.; Hayer, J.; Berg, M.; Jacobson, M. The intestinal eukaryotic virome in healthy and diarrhoeic Neonatal Piglets. PLoS ONE 2016, 11, e0151481. [CrossRef]

13. Kim, A.R.; Chung, H.C.; Kim, H.K.; Kim, E.O.; Nguyen, V.G.; Choi, M.G.; Yang, H.J.; Kim, J.A.; Park, B.K. Characterization of a complete genome of a circular single-stranded DNA virus from porcine stools in Korea. Virus Genes 2014, 48, 81-88. [CrossRef] [PubMed]

14. Oba, M.; Katayama, Y.; Naoi, Y.; Tsuchiaka, S.; Omatsu, T.; Okumura, A.; Nagai, M.; Mizutani, T. Discovery of fur seal feces-associated circular DNA virus in swine feces in Japan. J. Vet. Med. Sci. 2017, 79, 1664-1666. [CrossRef] [PubMed]

15. Sachsenröder, J.; Twardziok, S.; Hammerl, J.A.; Janczyk, P.; Wrede, P.; Hertwig, S.; Johne, R. Simultaneous identification of DNA and RNA viruses present in pig faeces using process-controlled deep sequencing. PLoS ONE 2012, 7, e34631. [CrossRef]

16. Shan, T.; Li, L.; Simmonds, P.; Wang, C.; Moeser, A.; Delwart, E. The fecal virome of pigs on a high-density farm. J. Virol. 2011, 85, 11697-11708. [CrossRef] [PubMed]

17. Shi, Z.; Liu, C.; Yang, H.; Chen, Y.; Liu, H.; Wei, L.; Liu, Z.; Jiang, Y.; He, X.; Wang, J. Fur seal feces-associated circular DNA virus identified in pigs in Anhui, China. Virol. Sin. 2021, 36, 25-32. [CrossRef] [PubMed]

18. Sikorski, A.; Arguello-Astorga, G.R.; Dayaram, A.; Dobson, R.C.; Varsani, A. Discovery of a novel circular single-stranded DNA virus from porcine faeces. Arch. Virol. 2013, 158, 283-289. [CrossRef]

19. Sun, W.; Wang, W.; Cao, L.; Zheng, M.; Zhuang, X.; Zhang, H.; Yu, N.; Tian, M.; Lu, H.; Jin, N. Genetic characterization of three porcine circovirus-like viruses in pigs with diarrhoea in China. Transbound. Emerg. Dis. 2021, 68, 289-295. [CrossRef] [PubMed]

20. Tochetto, C.; Varela, A.P.M.; Lima, D.A.; Loiko, M.R.; Scheffer, C.M.; Paim, W.P.; Cerva, C.; Schmidt, C.; Cibulski, S.P.; Ortiz, L.C.; et al. Viral DNA genomes in sera of farrowing sows with or without stillbirths. PLoS ONE 2020, 15, e0230714. [CrossRef] [PubMed]

21. Zhang, B.; Tang, C.; Yue, H.; Ren, Y.; Song, Z. Viral metagenomics analysis demonstrates the diversity of viral flora in piglet diarrhoeic faeces in China. J. Gen. Virol. 2014, 95, 1603-1611. [CrossRef]

22. Djikeng, A.; Halpin, R.; Kuzmickas, R.; Depasse, J.; Feldblyum, J.; Sengamalay, N.; Afonso, C.; Zhang, X.; Anderson, N.G.; Ghedin, E.; et al. Viral genome sequencing by random priming methods. BMC Genom. 2008, 9, 5. [CrossRef]

23. Buchfink, B.; Xie, C.; Huson, D.H. Fast and sensitive protein alignment using DIAMOND. Nat. Methods 2015, 12, 59-60. [CrossRef] [PubMed]

24. Huson, D.H.; Beier, S.; Flade, I.; Górska, A.; El-Hadidi, M.; Mitra, S.; Ruscheweyh, H.J.; Tappu, R. MEGAN community edition-interactive exploration and analysis of large-scale microbiome sequencing data. PLoS Comput. Biol. 2016, 12, e1004957. [CrossRef]

25. Guindon, S.; Dufayard, J.F.; Lefort, V.; Anisimova, M.; Hordijk, W.; Gascuel, O. New algorithms and methods to estimate maximum-likelihood phylogenies: Assessing the performance of PhyML 3.0. Syst. Biol. 2010, 59, 307-321. [CrossRef]

26. Tamura, K.; Stecher, G.; Peterson, D.; Filipski, A.; Kumar, S. MEGA6: Molecular Evolutionary Genetics Analysis version 6.0. Mol. Biol. Evol. 2013, 30, 2725-2729. [CrossRef] 
27. Martin, D.P.; Murrell, B.; Golden, M.; Khoosal, A.; Muhire, B. RDP4: Detection and analysis of recombination patterns in virus genomes. Virus Evol. 2015, 1, vev003. [CrossRef] [PubMed]

28. Sikorski, A.; Dayaram, A.; Varsani, A. Identification of a novel circular DNA virus in New Zealand fur seal (Arctocephalus forsteri) fecal matter. Genome Announc. 2013, 1, e00558-13. [CrossRef] [PubMed]

29. Guo, Z.; He, Q.; Tang, C.; Zhang, B.; Yue, H. Identification and genomic characterization of a novel CRESS DNA virus from a calf with severe hemorrhagic enteritis in China. Virus Res. 2018, 255, 141-146. [CrossRef] [PubMed]

30. Cheung, A.K. Porcine circovirus: Transcription and DNA replication. Virus Res. 2012, 164, 46-53. [CrossRef]

31. Kaszab, E.; Lengyel, G.; Marton, S.; Dán, Á.; Bányai, K.; Fehér, E. Occurrence and genetic diversity of CRESS DNA viruses in wild birds: A Hungarian study. Sci. Rep. 2020, 10, 7036. [CrossRef]

32. Nath, B.K.; Das, S.; Roby, J.A.; Sarker, S.; Luque, D.; Raidal, S.R.; Forwood, J.K. Structural perspectives of beak and feather disease virus and porcine circovirus proteins. Viral Immunol. 2021, 34, 49-59. [CrossRef] [PubMed]

33. Blomström, A.; Fossum, C.; Wallgren, P.; Berg, M. Viral metagenomic analysis displays the co-infection situation in healthy and PMWS affected pigs. PLOS ONE 2016, 11, e0166863. [CrossRef]

34. Kaszab, E.; Marton, S.; Forró, B.; Bali, K.; Lengyel, G.; Bányai, K.; Fehér, E. Characterization of the genomic sequence of a novel CRESS DNA virus identified in Eurasian jay (Garrulus glandarius). Arch. Virol. 2018, 163, 285-289. [CrossRef] [PubMed] 